\title{
Low-pass filtering or gain tuning free simple DC offset rejection technique for single and three-phase systems
}

Samet Biricik

Near East University - N.Cyprus, samet@biricikelektrik.com

Hafiz Ahmed

Mohamed Benbouzid

Follow this and additional works at: https://arrow.tudublin.ie/ittengart

Part of the Engineering Commons

\section{Recommended Citation}

Biricik, Samet; Ahmed, Hafiz; and Benbouzid, Mohamed, "Low-pass filtering or gain tuning free simple DC offset rejection technique for single and three-phase systems" (2020). Articles. 5.

https://arrow.tudublin.ie/ittengart/5

This Article is brought to you for free and open access by the School of Engineering at ARROW@TU Dublin. It has been accepted for inclusion in Articles by an authorized administrator of ARROW@TU Dublin. For more information, please contact arrow.admin@tudublin.ie, aisling.coyne@tudublin.ie,gerard.connolly@tudublin.ie. 


\title{
Low-pass filtering or gain tuning free simple DC offset rejection technique for single and three-phase systems
}

\author{
Hafiz Ahmed ${ }^{*, a, b}$, Samet Biricik ${ }^{\mathrm{c}, \mathrm{d}}$, Mohamed Benbouzid ${ }^{\mathrm{e}, \mathrm{f}}$ \\ ${ }^{a}$ School of Mechanical, Aerospace and Automotive Engineering, Coventry University, Coventry, UK \\ ${ }^{\mathrm{b}}$ Institute for Future Transport and Cities, Coventry University, Coventry, UK \\ ${ }^{\mathrm{c}}$ Department of Electrical and Electronics Engineering, European University of Lefke, North Cyprus, Mersin 10, Turkey \\ ${ }^{\mathrm{d}}$ School of Electrical and Electronic Engineering, Technological University Dublin, Dublin, Ireland \\ e UMR CNRS, University of Brest, 6027 IRDL, Brest 29238, France \\ ${ }^{\mathrm{f}}$ Shanghai Maritime University, Shanghai 201306, China
}

\section{A R T I C L E I N F O}

\section{Keywords:}

Phase estimation

Frequency estimation

DC offset

\begin{abstract}
A B S T R A C T
This paper aims to address the DC offset rejection problem in grid synchronization algorithm. A simple approach to estimate the unknown grid frequency in the presence of DC offset is proposed for this purpose. Some of the existing techniques available in the literature use either low-pass filter or an additional integrator to eliminate the DC offset. Both approaches require an additional parameter to tune. However, tuning the additional parameter is not straightforward. Moreover, tuning the overall system can be complicated due to the presence of DC offset rejection part. The proposed approach does not require any additional parameter to tune. By considering the orthogonal signal instead of the DC offset as an additional state, the proposed technique can efficiently estimate the unknown frequency of the grid. Application to both single and three-phase grids are provided. Comparative experimental results with DC offset rejection capable second-order generalized integrator (SOGI) phase-locked loop (PLL) (SOGI-PLL) demonstrate the effectiveness and suitability of the proposed technique.
\end{abstract}

\section{Introduction}

Many applications in power electronics, machine and drives (PEMD) area require accurate information of the grid voltage signal. Some of the application examples are: grid-connected converter [1-14], active power filter [15], dynamic voltage restorer [16,17], electric vehicle onboard charger [18], motor drive as smart load [19], to name a few. These applications require fast and accurate estimation of single and three-phase grid voltage parameters.

Existing literature on the accurate estimation of grid voltage parameter is huge and covers a wide variety of techniques. Some of the most popular techniques are: Kalman filter [20,21], discrete Fourier transform (DFT) [22,23], linear and nonlinear regression [21,24], adaptive notch filter (ANF) $[25,26]$, second order generalized integrator (SOGI) [27-33], Luenberger observer [34-36], open-loop techniques [37,38], phase-locked loop [39-44], to name a few.

DC offset presents a significant challenge for many of the techniques mentioned so far as they do not consider the presence of DC offset explicitly. As such, the presence of DC offset will give rise to steadystate ripple in the estimated parameters. There are two main sources of
DC offset. Firstly, DC offset can be introduced due to current transformation saturation [45]. Secondly, signal conversion process (analog to digital) can also introduce DC offset [43]. Since DC offset will introduce steady-state ripple, proper care needs to be taken to eliminate the effect of DC offset.

Many successful attempts have been made so far on adding DC offset rejection capability to grid synchronization techniques. Some of the commonly used approaches are: frequency adaptive pre-loop filtering [46-48], low-pass filtering [27,43], delayed signal cancellation (DSC) operator [49], additional integrator-based DC offset estimation [50,51], to name a few. Many of these techniques increase the overall system order by at least two and/or has large memory requirements. This increase the computational complexity of the overall closed-loop system. Moreover, parameter tuning can also be complicated. Out of the various techniques, low-pass filtering $[27,43]$ and additional integrator-based DC offset estimation [50] are two of the simplest technique available in the literature. Both techniques are first-order approach and has only one additional parameter to tune w.r.t. the standard approach i.e. without DC offset. However, tuning of the additional parameter is not straightforward.

\footnotetext{
* Corresponding author at: Institute for Future Transport and Cities, Coventry University, Coventry CV1 2TL, UK.

E-mail address: hafiz.h.ahmed@ieee.org (H. Ahmed).
} 


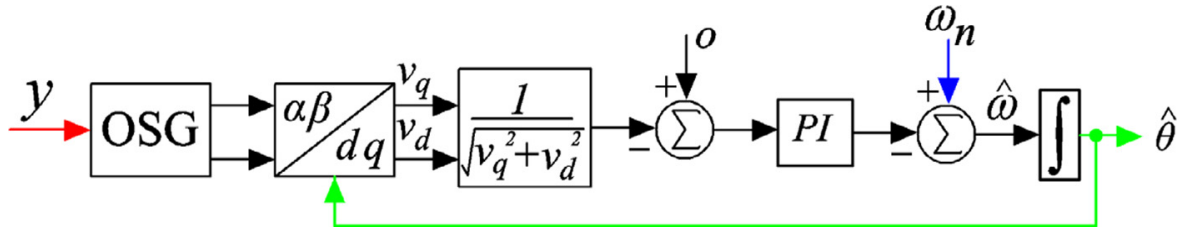

Fig. 1. Basic overview of orthogonal signal generatorbased single-phase PLL.

In the case of low-pass filtering $[27,43]$, the tuning parameter is the filter cut-off frequency. Cut-off frequency needs to be selected as lower than the nominal frequency of the grid. Low cut-off frequency increase the convergence time and decrease the disturbance sensitivity. As such cut-off frequency needs to be selected as trade-off between the transient performance and sensitivity to disturbance. Additional integrator-based DC offset estimation [50] technique considers the DC offset as an additional state. This approach is commonly used in state-space filtering techniques as well e.g. Kalman filter. This approach also requires an additional tuning parameter that controls the convergence of the DC offset estimation error. If this approach is used in conjunction with other notch filter (e.g. SOGI), then the DC offset estimation gain needs to be significantly smaller than that of the notch filter gain. In the literature, the DC offset estimation tuning parameter is selected as approximately one-fifth or smaller than the notch filter gain. In the presence of additional integrator, obtaining an accurate small-signal model for the gain tuning of the closed-loop system (including proportional integral controller of the PLL) can be difficult.

To overcome the limitation of the simple DC offset rejection techniques, a novel approach is considered in this work. In the proposed approach, no low-pass filtering or additional integrator-based DC offset estimation are involved. Instead of considering the DC offset as an additional state, the orthogonal signal is considered as an additional state. This eliminates the need of any additional tuning gain similar to $[50,52,53]$ or low-pass filtering similar to $[27,43]$. Once the orthogonal signal is generated, then the frequency can be estimated using any standard approach available in the literature. Tuning gain or low-pass filtering free orthogonal signal generation can be considered as a significant improvement over the existing literature.

The main contribution of this paper is the novel computationally simple DC offset rejection technique. The proposed technique does not require any gain tuning unlike $[50,52,53]$. It is also free from any filtering unlike $[27,43]$. The proposed technique has 1 gain to tune whereas PLL-based techniques have 4 and FLL-based techniques have 3 parameters to tune. This is an important advantage of the proposed technique over the existing literature.

The rest of this paper is organized as follows: Section 2 describes the development of the proposed technique. This Section also includes a short summary of two existing DC offset rejection techniques. Extension of the proposed technique to three-phase system is given in Section 3 . Experimental results are discussed in Section 4. Finally, Section 5 concludes this paper.

\section{Simple DC offset rejection technique development}

A single-phase grid voltage signal with DC offset can be written as:

$y=y_{0}+A \sin (\underbrace{\omega t+\phi}_{\theta})$

where $y_{0}, A, \omega, \phi$, and $\theta$ are the DC offset, amplitude, angular frequency, initial phase-angle, and the instantaneous phase, respectively. In grid synchronization application, the problem is to estimate the unknown angular frequency $\omega$ and the instantaneous phase $\theta$ from the measured grid voltage signal $y$. The unknown frequency is typically modeled as $\omega=\omega_{n}+\Delta \omega$, where $\omega_{n}$ is the nominal frequency (typically $\omega_{n}=100 \pi$ or $120 \pi$ ) and $\Delta \omega$ is the deviation from the nominal frequency. When the grid voltage signal does not contain any DC offset, there are plenty of techniques available in the literature to estimate $\omega$ and $\theta$. However, the presence of DC offset limits the applications of many of those techniques. In this Section, two simple techniques will be summarized that add DC offset rejection capability to grid synchronization algorithms.

\subsection{Review of two existing methods}

\subsubsection{Low-pass filtering-based DC offset rejection}

Many single-phase PLL techniques rely on the idea of synchronous reference frame - PLL (SRF-PLL) [54]. However, SRF-PLL uses Park transformation that requires two signals that are orthogonal. Singlephase system has only one measured signal. To overcome this limitation, single-phase PLL employs orthogonal signal generator ( $c f$. Fig. 1). However, in the presence of DC offset, traditional orthogonal signal generators (OSG) can not accurately generate the orthogonal signal resulting in estimation ripple in the estimated instantaneous phase and frequency. To overcome the effect of DC offset in second-order generalized integrator (SOGI)-type OSG, low-pass filtering (LPF) is first reported in Ciobotaru et al. [43]. Later on, some other modifications of this technique are also proposed in the literature e.g. [27]. Two demonstrate the working principle of this technique, let us consider the grid voltage signal $y=y_{0}+A \sin (\theta)$ and its orthogonal signal $y^{\perp}=-A \cos (\theta)$. To estimate $y^{\perp}$ from $y$, SOGI takes the following form:

$\dot{x}_{1}=x_{2} \omega$

$\dot{x}_{2}=-x_{1} \omega+k(\underbrace{y-x_{2}}_{\varepsilon}) \omega$

where $x_{1}$ and $x_{2}$ are the estimates of $y^{\perp}$ and $y$ and $k_{s}>0$ is the filter gain. When $y_{0}=0, x_{1}$ and $x_{2}$ asymptotically estimates $y^{\perp}$ and $y$ as the feedback error term $\varepsilon$ will converge to zero. However, in the presence of $y_{0}$, although $x_{2}$ will be able to estimate $y$, however, $x_{1}$ will not be able to estimate exactly $y^{\perp}$. It will estimate $y^{\perp}$ with some offset. In the presence of $y_{0}$, the solution of $x_{1}$ can be written as:

$$
\begin{aligned}
x_{1} & =\omega \int_{0}^{t} \underbrace{x_{2}(\tau)}_{\hat{y}(\tau)} d \tau \\
& =-A \cos (\theta)+\omega \int_{0}^{t} \hat{A}_{0}(\tau) d \tau
\end{aligned}
$$

Eq. (3) shows that $x_{1}$ is estimating $y^{\perp}$ with some offset. A simple lowpass filter can be used to eliminate the offset term from Eq. (3). The block diagram of the LPF-based DC offset rejection technique applied to SOGI filter is given in Fig. 2. The transfer function of the filter can be chosen as $\operatorname{LPF}(s)=\omega_{c} /\left(s+\omega_{c}\right)$, where $\omega_{c}$ is the cut-off frequency.

Transfer functions of the estimated signals in this case are given below:

$\frac{x_{2}}{y}(s)=\frac{k \omega s}{s^{2}+k \omega s+\omega^{2}}$

$\frac{x_{1}^{\star}}{y}(s)=\frac{-k \omega_{c} s^{2}+k \omega^{2} s}{s^{3}+\left(k \omega+\omega_{c}\right) s^{2}+\left(\omega^{2}+k \omega \omega_{c}\right) s+\omega^{2} \omega_{c}}$

The gain of the transfer function (4b) is zero at $s=0$ (i.e. the frequency of the offset term). As such the LPF can completely eliminate the DC offset at $x_{1}^{\star}$. However, in addition to the filter gain $k$, this technique introduces one more gain to tune which is the filter cut-off frequency. 


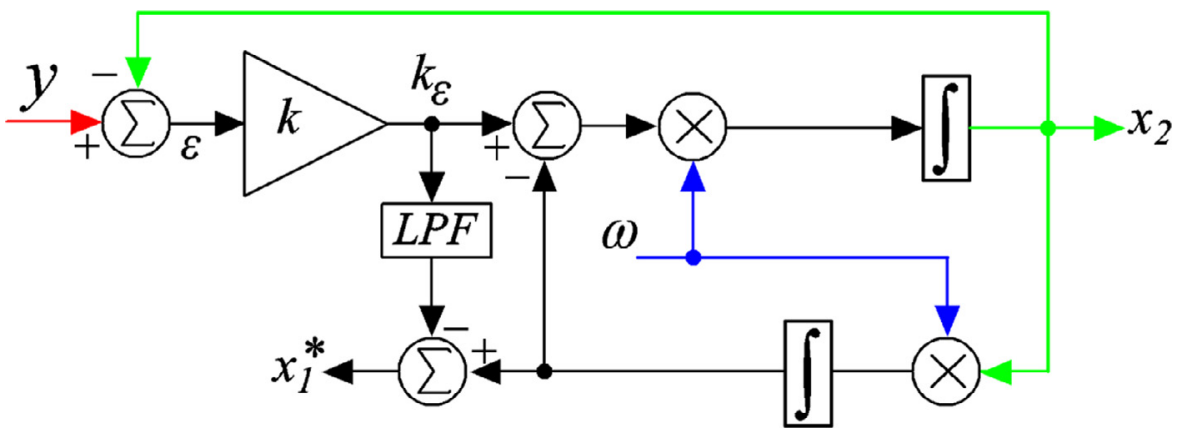

Fig. 2. Low-pass filter-based DC offset rejection technique [43].

The cut-off frequency significantly affect the performance of this technique. Moreover, this technique can be prone to error due to high frequency harmonics.

\subsubsection{Extended state-based DC offset rejection}

This technique was first reported in Karimi-Ghartemani et al. [50]. In this case, the DC offset is considered as an additional state. To demonstrate the working principle of this technique, let us consider the state variables as $x_{1}=-A \cos (\theta), x_{2}=A \sin (\theta)$, and $x_{3}=y_{0}$. The following SOGI filter can be considered to estimate the orthogonal signal:

$\dot{x}_{1}=x_{2} \omega$

$\dot{x}_{2}=-x_{1} \omega+k\left(y-x_{2}-x_{3}\right) \omega$

$\dot{x}_{3}=k_{d c}\left(y-x_{2}-x_{3}\right) \omega$

where $k$ is SOGI gain and $k_{d c}$ is the DC offset estimation gain. Block diagram of this technique is given in Fig. 3.

The transfer functions in this case are given below:

$\frac{x_{1}}{y}(s)=\frac{k \omega^{2} s}{s^{3}+\left(k+k_{d c}\right) \omega s^{2}+\omega^{2} s+k_{d c} \omega^{3}}$

$\frac{x_{2}}{y}(s)=\frac{k \omega s^{2}}{s^{3}+\left(k+k_{d c}\right) \omega s^{2}+\omega^{2} s+k_{d c} \omega^{3}}$

$\frac{x_{3}}{y}(s)=\frac{k \omega\left(s^{2}+\omega^{2}\right)}{s^{3}+\left(k+k_{d c}\right) \omega s^{2}+\omega^{2} s+k_{d c} \omega^{3}}$

From the transfer functions (6a) and (6b), one can see that both acts as a band-pass filter and $x_{1}$ introduces $90^{\circ}$ phase-shift i.e. generates orthogonal signal. Similar to LPF-based technique, this technique has also one additional gain to tune w.r.t. standard SOGI filter. It is suggested in the literature that the gain $k_{0}$ should be chosen significantly smaller than $k$ to obtain a trade-off between fast dynamic response and good transient performance. Moreover, when this filter will be used inside single-phase SRF-PLL (Fig. 1), tuning the closed-loop system (including PI controller gains) can be very complicated. In order to introduce a systematic gain-tuning procedure, first a small-signal model of the PLL system needs to be developed. To do this, time-domain solutions of the state variables $x_{1}$ and $x_{2}$ are to be obtained from eq. (6a) and (6b). However, by substituting the value of $y(s)$ in these equations, one get a fifth-order denominator polynomial. Obtaining the inverse Laplace solution of such a high-order polynomial is not straightforward. This limits the development of systematic design procedure. Moreover, tuning $k$ and $k_{0}$ are also not straightforward.

\subsection{Proposed technique}

The proposed technique uses state-space method. To develop the estimator, let us consider the state variables as, $x_{1}=-A \cos (\theta)$, $x_{2}=y_{0}+A \sin (\theta)$ and $x_{3}=A \sin (\theta)$. Then the following estimator can be designed to generate orthogonal signal:

$\dot{x}_{1}=x_{2} \omega-\left(y-x_{3}\right) \omega$

$\dot{x}_{2}=-x_{1} \omega+k\left(y-x_{2}\right) \omega$

$\dot{x}_{3}=-x_{1} \omega$

where $k>0$ is the tuning gain. Block diagram of the proposed orthogonal signal generator is given in Fig. 4.

Unlike the reviewed techniques in Section 2.1, proposed technique has only one gain to tune. Its transfer functions are given below:

$\frac{x_{1}}{y}(s)=\frac{-\omega s^{2}}{s^{3}+k \omega s^{2}+2 \omega^{2} s+k \omega^{3}}$
$\frac{x_{2}}{y}(s)=\frac{k \omega s^{2}+\omega^{2} s+k \omega^{3}}{s^{3}+k \omega s^{2}+2 \omega^{2} s+k \omega^{3}}$

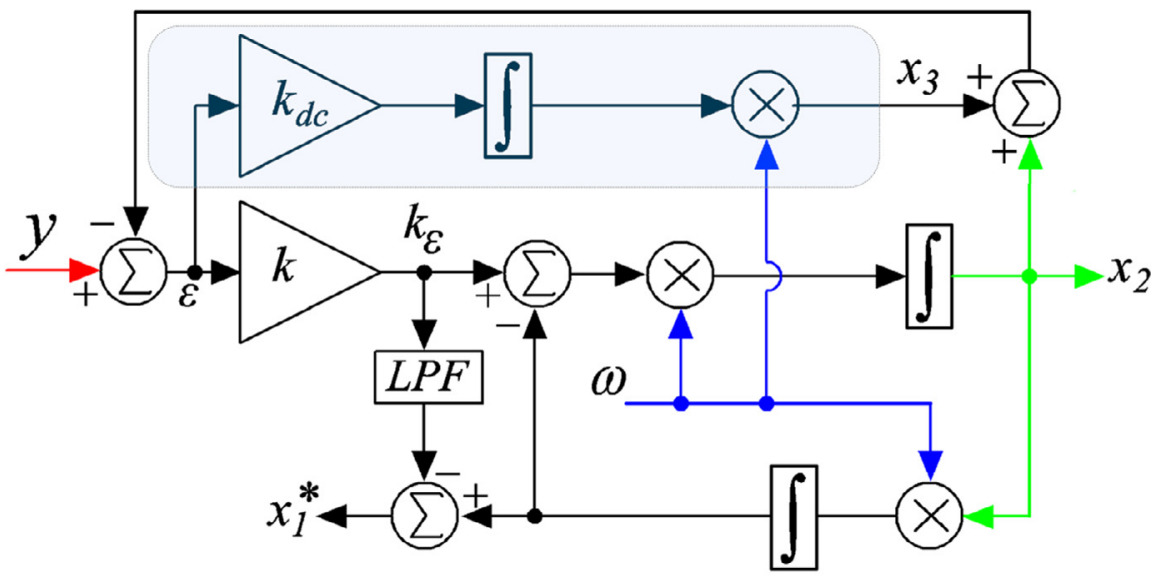

Fig. 3. Extended state-based DC offset rejection technique [43]. 


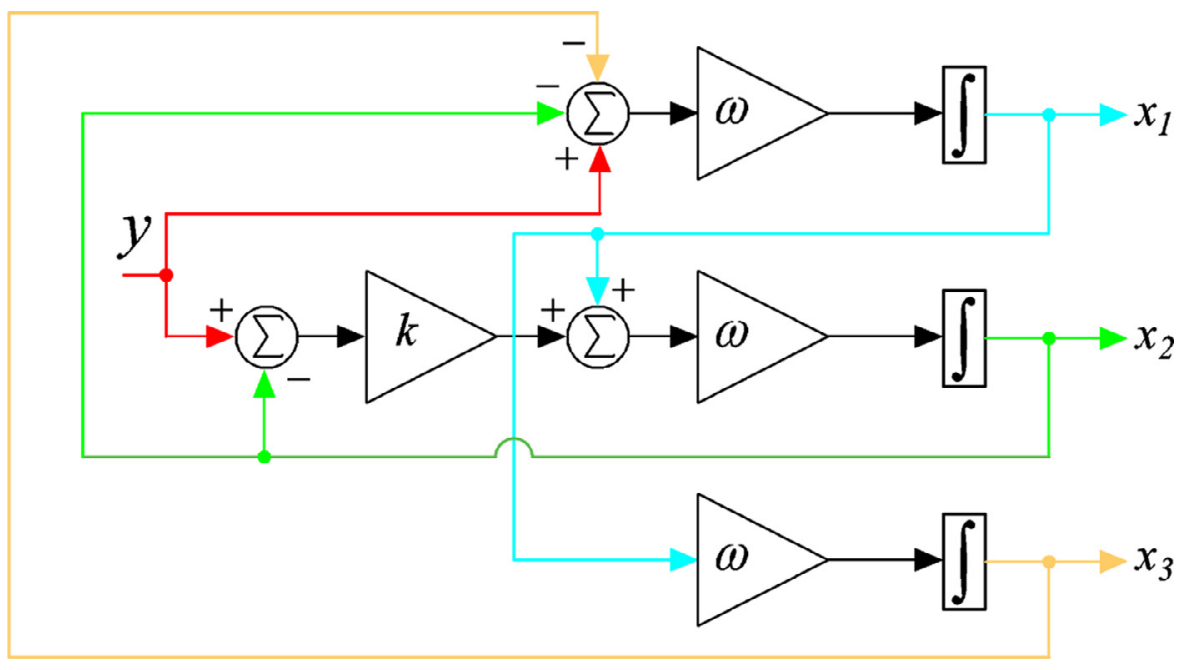

Fig. 4. Proposed DC rejection capable orthogonal signal generator.
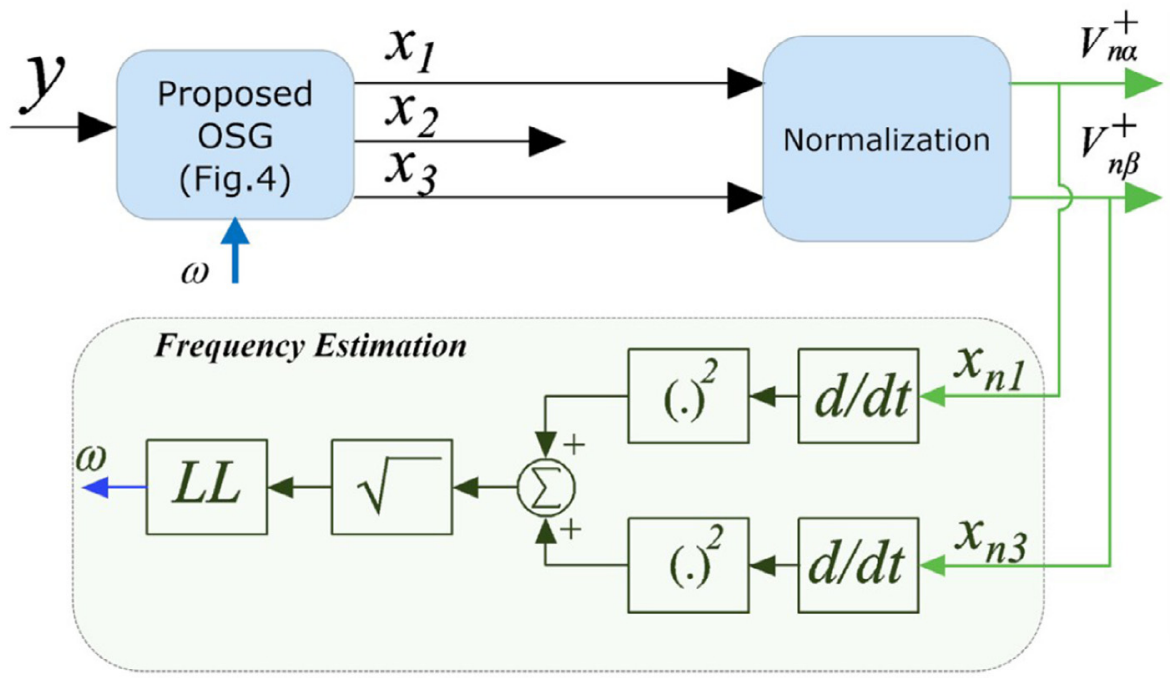

Fig. 5. Block diagram of the proposed technique for a single-phase system.

$\frac{x_{3}}{y}(s)=\frac{\omega^{2} s}{s^{3}+k \omega s^{2}+2 \omega^{2} s+k \omega^{3}}$

From the transfer functions ( $8 a$ ) and (8c), it can be seen that they act as a band-pass filter and generates the orthogonal signal without any additional gain or low-pass filtering. As such, the proposed technique can be considered as a significantly simpler approach than similar other techniques reported in the literature.

\subsubsection{Frequency estimation}

The proposed technique requires the angular frequency of the grid voltage signal which is unknown in practice. To estimate that unknown frequency, a PLL or FLL can be connected to the proposed OSG as shown in Fig. 1. However, this will require the tuning of the PLL gains or the FLL gain. This necessitates the development of a small-signal model of the closed-loop system. To overcome this issue, derivativebased frequency estimation technique can be used. This type of approach is often used in various variants of open-loop grid synchronization technique e.g. [37,38]. This approach will be considered here as well. State variables $x_{1}$ and $x_{3}$ can be directly used in estimating the frequency. However, this will make the convergence slower in the presence of voltage sag. This can be avoided by using normalization. Normalization will give two signals with unitary amplitude. The normalization process can be written as: $x_{n 1}=\frac{x_{1}}{\sqrt{x_{1}^{2}+x_{3}^{2}}}=-\cos (\omega t+\phi)$

$x_{n 3}=\frac{x_{3}}{\sqrt{x_{1}^{2}+x_{3}^{2}}}=\sin (\omega t+\phi)$

By calculating the time-derivative of the normalized signals given in Eq. (9), the following signals can be obtained:

$\dot{x}_{n 1}=\omega \sin (\omega t+\phi)$

$\dot{x}_{n 3}=\omega \cos (\omega t+\phi)$

Then the unknown frequency $\omega$ can be obtained by using the following formula:

$\omega^{2}=x_{n 1}^{2}+x_{n 3}^{2}$

The frequency obtained through direct derivative estimation may show some fluctuations. A lead-lag smoother can be used to reduce the fluctuation. The following lead-lag filter is recommended in Safa et al. [38]:

$L L(s)=\frac{1+5 \times 10^{-3} s}{1+20 \times 10^{-3} s}$

Lead-lag filter (12) can be used if fluctuation reduction is required. An overview of the proposed grid synchronization scheme is given in 


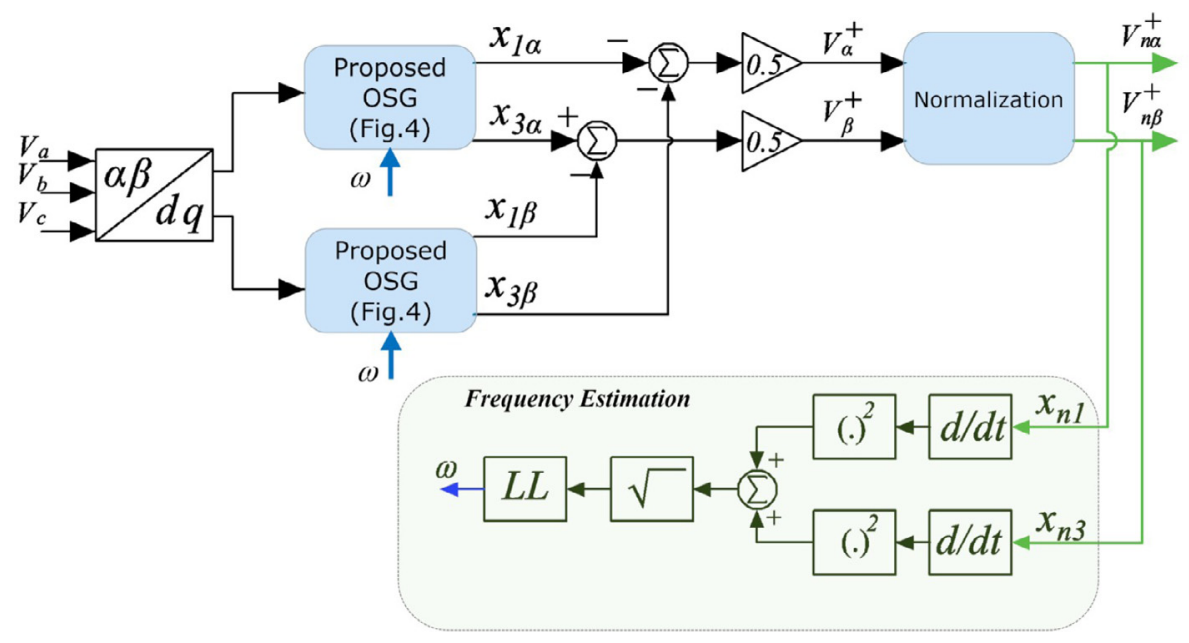

Fig. 6. Block diagram of the proposed technique for a three-phase system.

Fig. 5.

\section{Extension to three-phase case}

The proposed technique as developed in Section 2.2 can be easily applied to a three-phase system. For this purpose, let us consider the following unbalanced three-phase grid voltage signals with DC offset:

$V_{a}=V_{a 0}+V^{+} \sin (\underbrace{\omega t+\phi^{+}}_{\theta^{+}})+V^{-} \sin (\underbrace{\omega t+\phi^{-}}_{\theta^{-}})$

$V_{b}=V_{b 0}+V^{+} \sin \left(\theta^{+}-\frac{2 \pi}{3}\right)+V^{-} \sin \left(\theta^{-}+\frac{2 \pi}{3}\right)$

$V_{c}=V_{c 0}+V^{+} \sin \left(\theta^{+}+\frac{2 \pi}{3}\right)+V^{-} \sin \left(\theta^{-}-\frac{2 \pi}{3}\right)$

where $V^{+}$and $V^{-}$are the positive and negative sequence amplitudes, $\phi^{+}$ and $\phi^{-}$are the positive and negative sequence initial phase-angles, and $V_{a 0}, V_{b 0}, V_{c 0}$ are the DC offsets in phase $a, b$, and $c$, respectively. By applying the Clarke transformation [55], three-phase grid voltages as given in Eq. (13) can be reduced to the following two signals:

$\left[\begin{array}{c}V_{\alpha} \\ V_{\beta}\end{array}\right]=\underbrace{\frac{2}{3}\left[\begin{array}{ccc}1 & \frac{-1}{2} & \frac{-1}{2} \\ 0 & \frac{\sqrt{3}}{2} & \frac{-\sqrt{3}}{2}\end{array}\right]}_{T_{\alpha \beta}}\left[\begin{array}{l}V_{a} \\ V_{b} \\ V_{c}\end{array}\right]$

$V_{\alpha}=V_{\alpha 0}+\underbrace{V^{+} \sin \left(\theta^{+}\right)}_{V_{\alpha}^{+}}+\underbrace{V^{-} \sin \left(\theta^{-}\right)}_{V_{\alpha}^{-}}$

$V_{\beta}=V_{\beta 0}+\underbrace{V^{-} \cos \left(\theta^{-}\right)}_{V_{\beta}^{-}}-\underbrace{V^{+} \cos \left(\theta^{+}\right)}_{V_{\beta}^{+}}$

where $V_{\alpha 0}=\frac{1}{3}\left(2 V_{a 0}-V_{b 0}-V_{c 0}\right)$ and $V_{\beta 0}=\frac{1}{\sqrt{3}}\left(V_{b 0}-V_{c 0}\right)$. In the case of unbalanced three-phase voltages, the objective is to estimate the positive sequence components (PSC) i.e. $V_{\alpha}^{+}$and $V_{\beta}^{+}$. The proposed technique can be used to extract the PSC from the unbalanced three-phase voltages. By passing $V_{\alpha}$ and $V_{\beta}$ individually through the proposed orthogonal signal generator, the following signals can be obtained:

$x_{1 \alpha}=-V^{+} \cos \left(\theta^{+}\right)-V^{-} \cos \left(\theta^{-}\right)$

$x_{3 \alpha}=V^{+} \sin \left(\theta^{+}\right)+V^{-} \sin \left(\theta^{-}\right)$

$x_{1 \beta}=V^{-} \sin \left(\theta^{-}\right)-V^{+} \sin \left(\theta^{+}\right)$

$x_{3 \beta}=V^{-} \cos \left(\theta^{-}\right)-V^{+} \cos \left(\theta^{+}\right)$

From the signals obtained by Eq. (16), the PSC can be calculated as:
$V_{\alpha}^{+}=\frac{x_{3 \alpha}-x_{1 \beta}}{2}, V_{\beta}^{+}=-\frac{x_{1 \alpha}+x_{3 \beta}}{2}$

Once the positive sequence components are obtained, the unknown frequency $\omega$ can be calculated using the same approach as described in Section 2.2.1. For this purpose, normalized signals need to be computed and are given below:

$V_{n \alpha}^{+}=\frac{V_{\alpha}^{+}}{\sqrt{V_{\alpha}^{+}+V_{\beta}^{+}}}=\sin \left(\omega t+\phi^{+}\right)$

$V_{n \beta}^{+}=\frac{V_{\beta}^{+}}{\sqrt{V_{\alpha}^{+}+V_{\beta}^{+}}}=\cos \left(\omega t+\phi^{+}\right)$

Then the time-derivative of the normalized signals can be computed as:

$\dot{V}_{n \alpha}^{+}=\omega \cos \left(\omega t+\phi^{+}\right)$

$\dot{V}_{n \beta}^{+}=-\omega \sin \left(\omega t+\phi^{+}\right)$

Finally, the unknown frequency can be computed as:

$\omega^{2}=\left(\dot{V}_{n \alpha}^{+}\right)^{2}+\left(\dot{V}_{n \beta}^{+}\right)^{2}$

An overview of the proposed technique for the three-phase case is given in Fig. 6.

\section{Results and discussions}

To verify the effectiveness of the proposed technique, in this Section experimental studies are considered. As a comparative technique, an improved extended SOGI PLL (as described in Section 2.1.2) [52,53] is considered. Improved SOGI-PLL (ISOGI-PLL) parameters are chosen as: $k=\sqrt{2}, k_{d c}=0.22, k_{p}=4 / t_{s}$, and $k_{i}=k_{p}^{2} / 4 \zeta^{2}$ where $t_{s}=60 \mathrm{msec}$. and the damping ratio $\zeta=1 / \sqrt{2}$. The parameter of the proposed technique is selected as the same as improved SOGI-PLL i.e. $k=\sqrt{2}$. Both techniques are implemented in Matlab/Simulink with a sampling frequency of $10 \mathrm{kHz}$ and Trapezoidal method has been selected as the discretization technique for the continuous integrators.

\subsection{Hardware-in-the loop experimental study}

This section presents dSPACE 1104 board-based Hardware-in-theloop (HIL) experimental study.

\subsubsection{Single-phase grid voltage}

To test the performance of the proposed technique, four challenging 

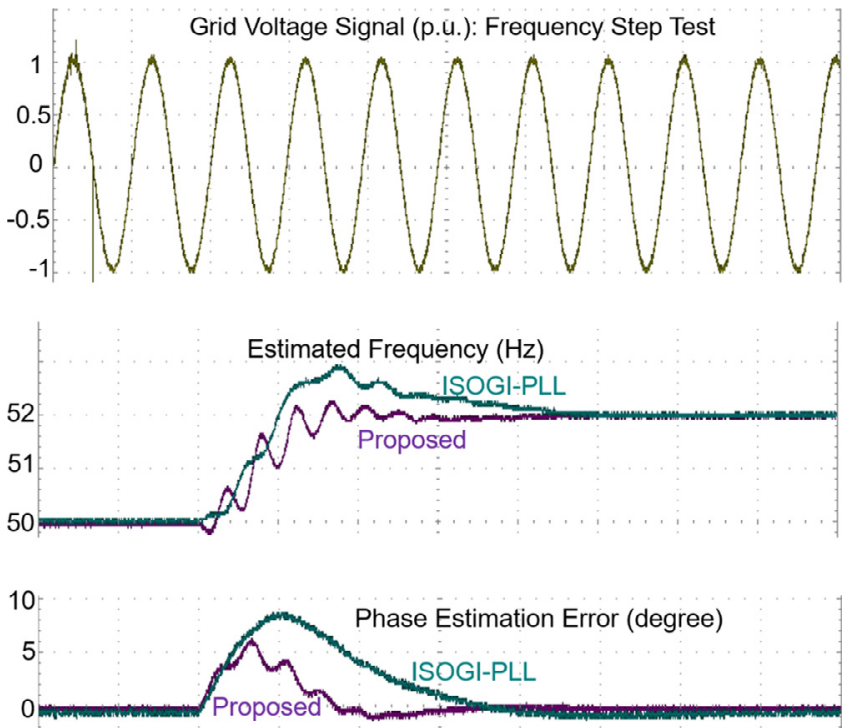

Fig. 7. HIL experimental results for Test SP1: $+2 \mathrm{~Hz}$ frequency jump.

test scenarios are considered in the single-phase case. The considered test-cases are:

- SP1: $+2 \mathrm{~Hz}$ frequency jump

- SP2: +0.15 p.u. DC offset jump

- SP3: $+45^{\circ}$ phase jump

- SP4: -0.4 p.u. voltage sag

Fig. 7 shows the grid voltage signal, estimated frequencies, and the phase estimation errors for test case SP1. Results show that both techniques reacted very fast to the change in grid frequency. By considering a steady-state band of $\pm 0.1 \mathrm{~Hz}$, the proposed technique converged in $\approx 1.5$ cycles while the ISOGI-PLL took $\approx 3$ cycles. The proposed technique demonstrated insignificant peak overshoot, however, the same can not be said for ISOGI-PLL. ISOGI-PLLs convergence time can be reduced by selecting a lower settling time for the PI controller tuning. However, this will deteriorate the transient performance. Fast convergence of the frequency generally implies fast convergence for the instantaneous phase estimation error. This is clearly demonstrated in Fig. 7. The phase estimation error for the proposed technique converged in $\approx 1.5$ cycles with peak overshoot of $6.2^{\circ}$ while ISOGI-PLLs peak overshoot is 1.5 times of the proposed technique.

The next test considers DC offset. In this case, a DC offset of +0.15 p.u. is suddenly added to the grid voltage signal. Fig. 8 shows the grid voltage signal, estimated frequencies, and the phase estimation errors for the case SP2. Both techniques quickly detected the change in DC offset value and reacted accordingly. The frequency estimated by the proposed technique converged in $\approx 1.25$ cycles with a peak overshoot of $0.48 \mathrm{~Hz}$ while ISOGI-PLL converged in $\approx 2.5$ cycles with a peak overshoot of $1.4 \mathrm{~Hz}$. This implies that the proposed technique converged two times faster with $67 \%$ less peak overshoot in frequency. The proposed techniques peak overshoot is $1.88^{\circ}$ while for ISOGI-PLL the peak overshoot is $2.8^{\circ}$ which is $\approx 1.5$ times more than the proposed technique.

Due to fault in the grid, the phase-angle may experience sudden jump. This situation is considered in test case SP3 where the grid voltage's phase-angle suddenly experienced $+45^{\circ}$ jump. Fig. 9 shows the grid voltage signal, estimated frequencies, and the phase estimation errors for test case SP3. The frequency estimated by the proposed technique converged in $\approx 3$ cycles with a peak overshoot of $7.5 \mathrm{~Hz}$ while ISOGI-PLL took $\approx 5$ cycles with a peak overshoot of $8.8 \mathrm{~Hz}$. Phase estimation errors convergence times are similar to frequency estimation case. Experimental results as shown in Fig. 9 demonstrate
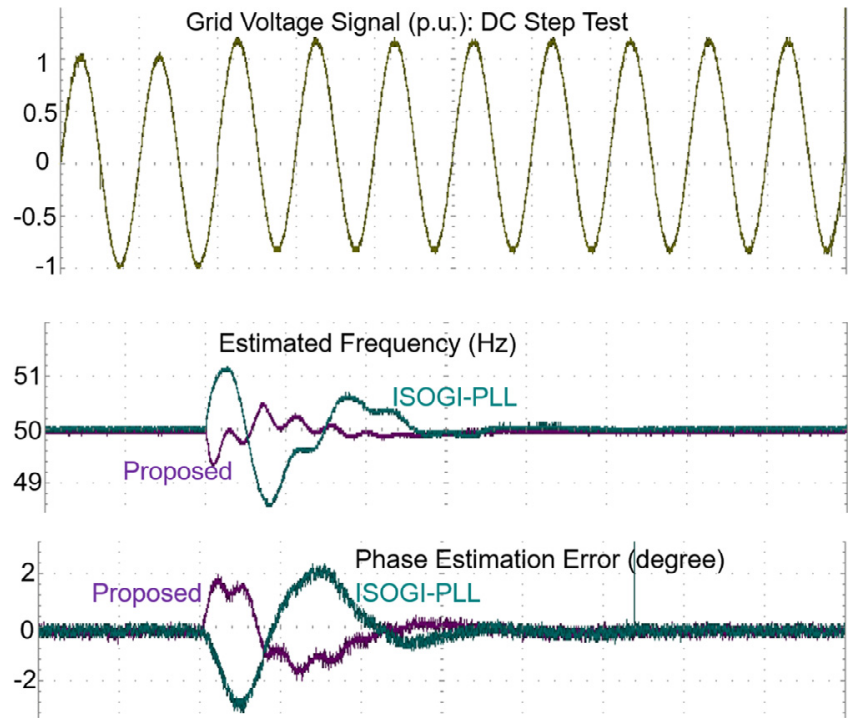

Fig. 8. HIL experimental results for test case SP2: +0.15 p.u. DC offset jump.
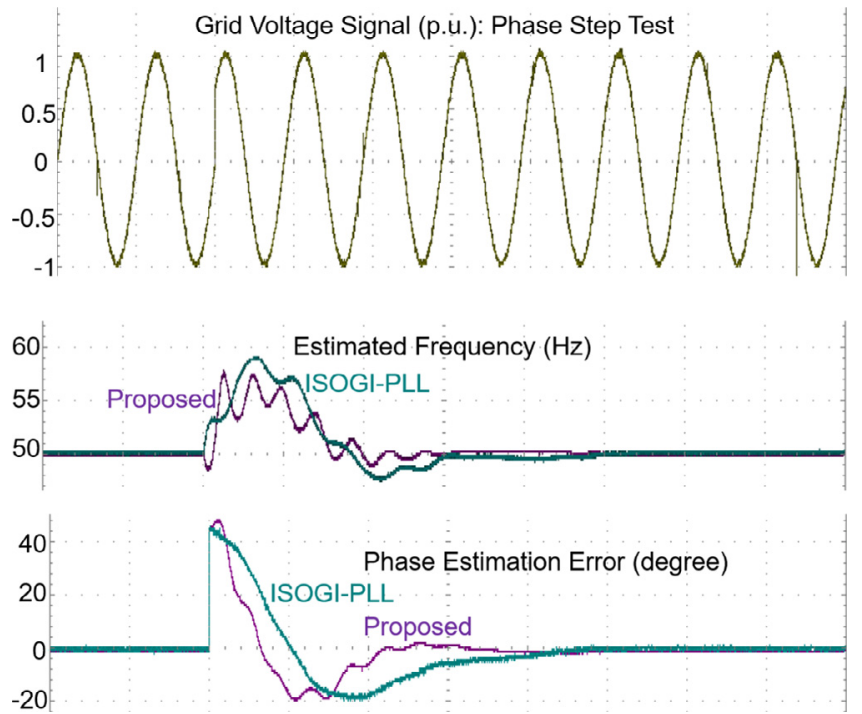

Fig. 9. HIL experimental results for test case SP3: $+45^{\circ}$ phase jump.

the suitability of the proposed technique over ISOGI-PLL.

The final test case considers voltage sag. Fig. 10 shows the grid voltage signal, estimated frequencies, and the phase estimation errors for test case SP4. Experimental results show that both techniques have similar peak overshoot in the frequency estimation case, however, the proposed technique converged faster. In the case of phase estimation error, both techniques have similar performances. It is to be noted here that the proposed technique has only one parameter to tune while ISOGI-PLL has two parameters to tune in the ISOGI part.

All the experimental results shown in this Section demonstrate the effectiveness and suitability of the proposed technique. The proposed technique either performed better or similar to ISOGI-PLL despite having only one parameter to tune.

\subsubsection{Three-phase grid voltages}

In this Section, the performance of the proposed technique will be considered for a three-phase system. For this purpose, the following test cases are considered:

- TP1: $-2 \mathrm{~Hz}$ frequency jump

- TP2: -0.1 p.u. DC offset in phase b and c. 

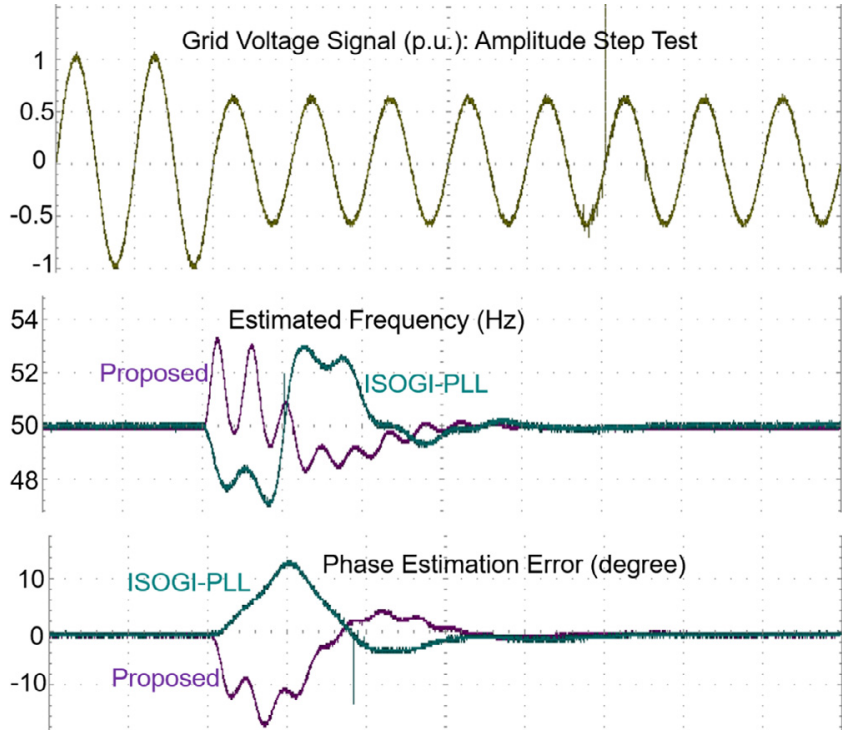

Fig. 10. HIL experimental results for test case SP4: -0.4 p.u. voltage sag.

- TP3: Balanced to unbalanced step test

- TP4: Harmonics step test

Fig. 11 shows the grid voltage signal, estimated frequencies, and the phase estimation errors for the test case TP1. Results show that the frequency estimated by the proposed technique converged in $\approx 1.5$ cycles with negligible overshoot. However, ISOGI-PLL took more than $\approx 3$ cycles with $\approx 0.75 \mathrm{~Hz}$ overshoot. As the proposed technique converged significantly faster than ISOGI-PLL, the phase estimation error by the proposed technique also converged significantly faster with lower peak overshoot w.r.t. ISOGI-PLL. As a result, it can be said that the proposed technique is not only easy to tune but also has fast convergence.

DC offset may not be avoided in many cases. The next test case considers sudden addition of DC offset to phase $b$ and $c$ while phase $a$ remains unaffected. Fig. 12 shows the grid voltage signal, estimated frequencies, and the phase estimation errors for test case TP2. The frequency estimated by the proposed technique permanently entered within the band $\pm 0.1 \mathrm{~Hz}$ within just $4 \mathrm{msec}$. with a peak overshoot of only $0.14 \mathrm{~Hz}$. The frequency estimated by the ISOGI-PLL converged in
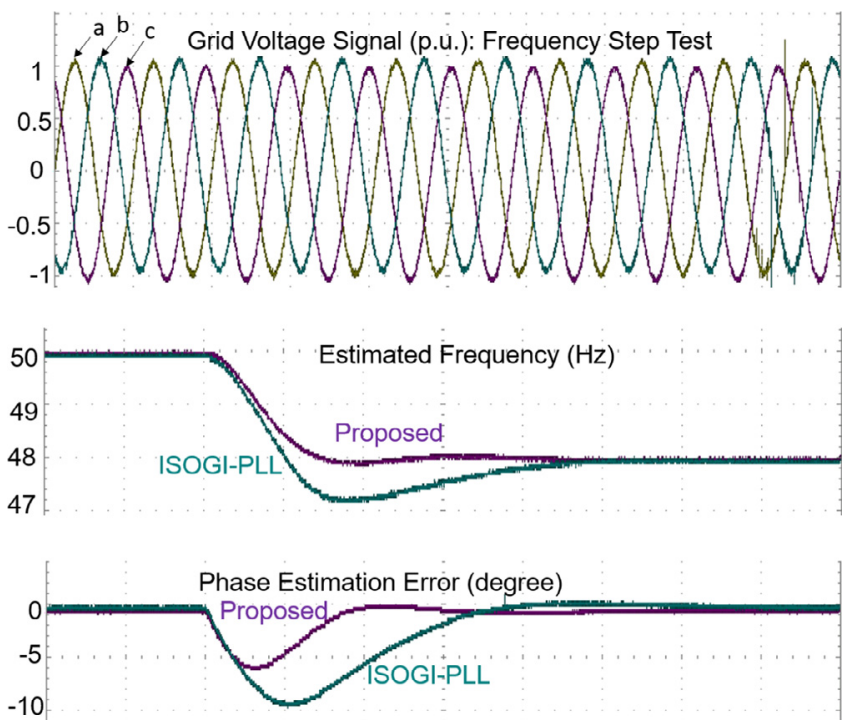

Fig. 11. HIL experimental results for test case TP1: $-2 \mathrm{~Hz}$ frequency jump.
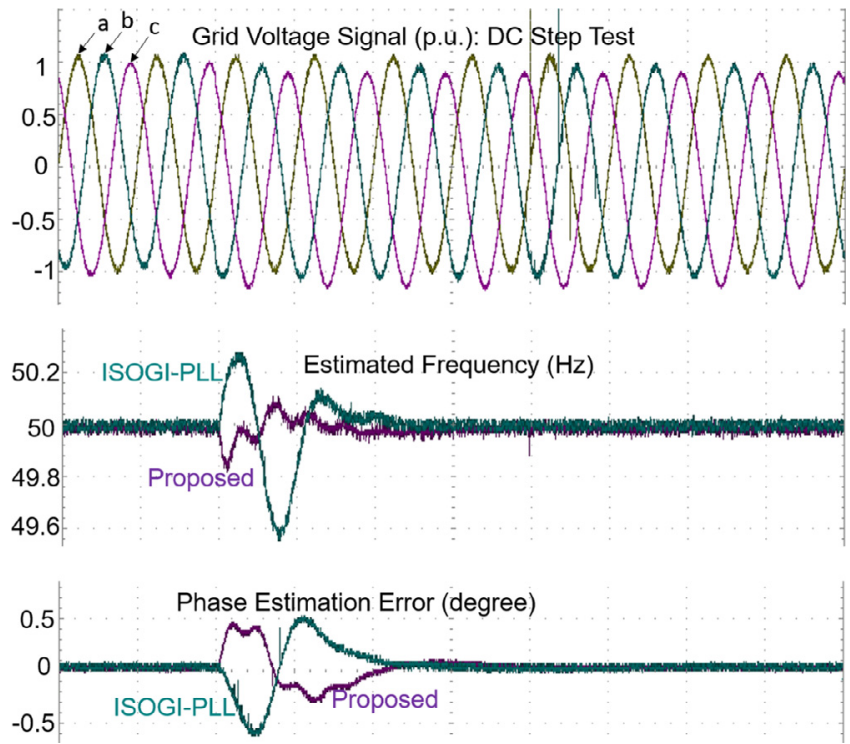

Fig. 12. HIL experimental results for test case TP2: -0.1 p.u. DC offset jump in phase $b$ and $c$.

$\approx 1.25$ cycle with a peak overshoot of $0.4 \mathrm{~Hz}$. Since the estimated frequencies did not deviate much from the actual frequency, the phase estimation error also did not deviate much from the actual value. The proposed technique showed a peak overshoot of $0.4^{\circ}$ while the peak overshoot of ISOGI-PLL is $\approx 1.5$ times higher at $\approx 0.62^{\circ}$.

Unbalanced three-phase voltages are not that uncommon in power grid. As such any grid synchronization algorithm should be able to handle unbalanced voltages in three-phase system. Test case TP3 considers unbalanced voltages. Initially, the grid voltages had only positive sequence component $V^{+}=1 \angle 0^{\circ}$. Suddenly, after the fault, negative sequence voltages are introduced in the grid. The post-fault grid voltages are comprised of positive sequence $0.65 \angle 60^{\circ}$ and negative sequence $0.35 \angle-40^{\circ}$. In addition, the frequency also jumped $-2 \mathrm{~Hz}$. Fig. 13 shows the grid voltage signal, estimated frequencies, and the phase estimation errors for test case TP3. Experimental results show that both
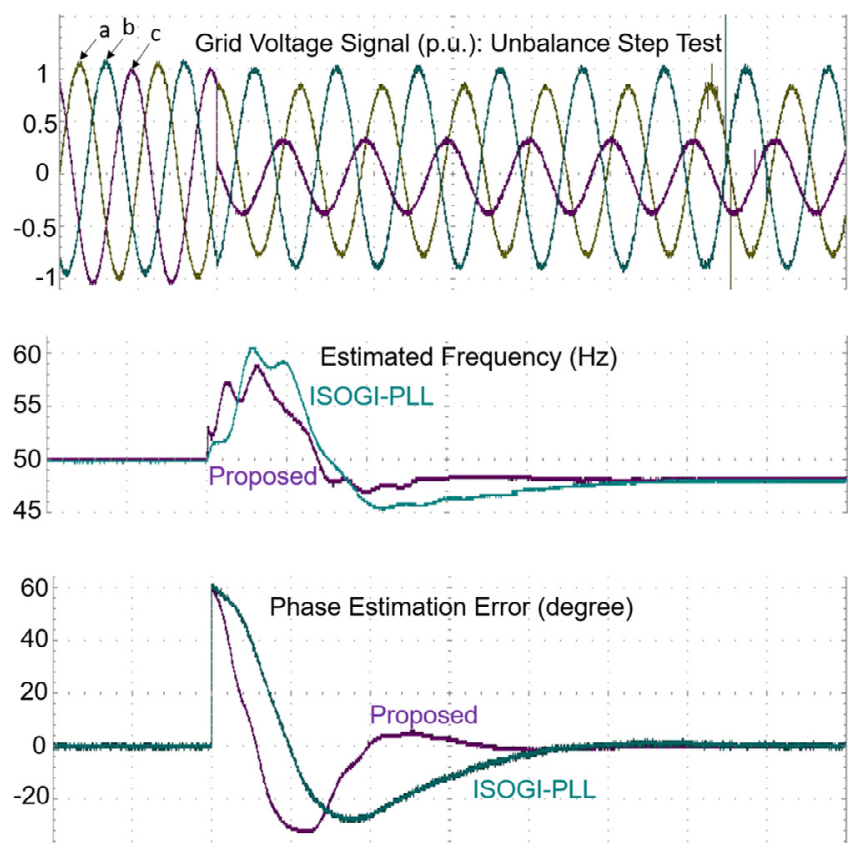

Fig. 13. HIL experimental results for test case TP3: Balanced to unbalanced voltages step test. 
Table 1

Details of the distorted grid voltages used in test case TP4.

\begin{tabular}{lll}
\hline Component & Magnitude (p.u.) & Phase \\
\hline Positive sequence $(50 \mathrm{~Hz})$ & 0.711 & $5^{\circ}$ \\
Negative sequence $(50 \mathrm{~Hz})$ & 0.232 & $50.1^{\circ}$ \\
3rd harmonics & 0.15 & $40^{\circ}$ \\
5th harmonics & 0.18 & $40^{\circ}$ \\
7th harmonics & 0.17 & $180^{\circ}$ \\
11th harmonics & 0.08 & $180^{\circ}$ \\
Subharmonic $(30 \mathrm{~Hz})$ & 0.07 & $0^{\circ}$ \\
Interharmonic $(160 \mathrm{~Hz})$ & 0.06 & $-45^{\circ}$
\end{tabular}

techniques quickly detected the unbalanced voltages and the change in frequency. The frequency estimated by the proposed technique converged in $\approx 3$ cycles while it is $\approx 5$ cycles for ISOGI-PLL. Moreover, the peak frequency overshoot is also two times more for the ISOGI-PLL. These results show the effectiveness of the proposed technique in the case of unbalanced step test.

Harmonics is another important factor that may be unavoidable in some cases. Test case TP4 considers distorted grid voltages. Considered harmonics voltages are given in Table 1 . In addition, frequency jump of $+2 \mathrm{~Hz}$ is considered as well. Fig. 14 shows the grid voltage signal, estimated frequencies, and the phase estimation errors for test case TP4.Experimental results show that both techniques have similar convergence time for frequency estimation, however, the proposed technique has lower peak overshoot. The phase estimation error convergence time is also very similar for the comparative techniques, however, the peak overshoot is $7.3^{\circ}$ for the proposed technique while it is $12.5^{\circ}$ for ISOGI-PLL. This shows the performance improvement by the proposed technique in terms of peak overshoot.

All the experimental results presented in this Section show that similar to the single-phase case, proposed technique either performed better or similar to ISOGI-PLL in the three-phase case. This demonstrates the suitability and effectiveness of the proposed technique.

\subsection{Experimental study}

The experimental setup used in this work is given in Fig. 15. To emulate the adverse grid voltage signal, a DC motor is coupled to the
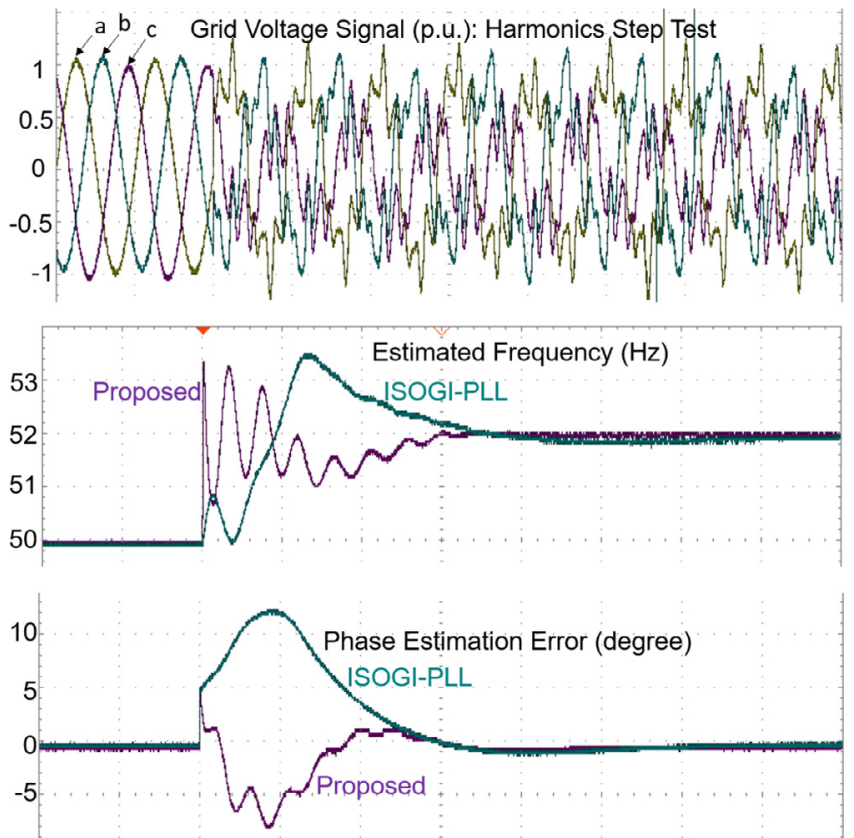

Fig. 14. HIL experimental results for test case TP4: Harmonics step test.

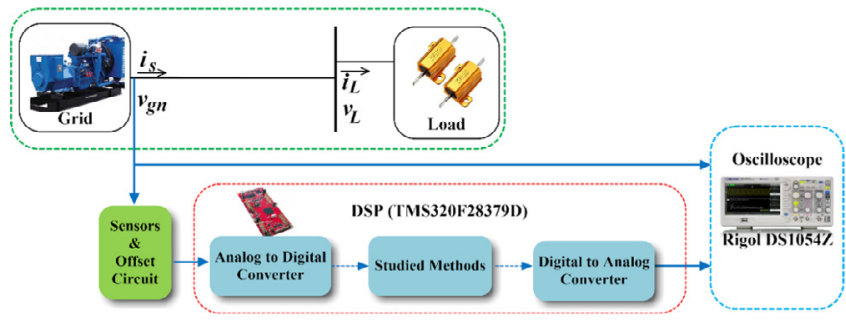

(a)

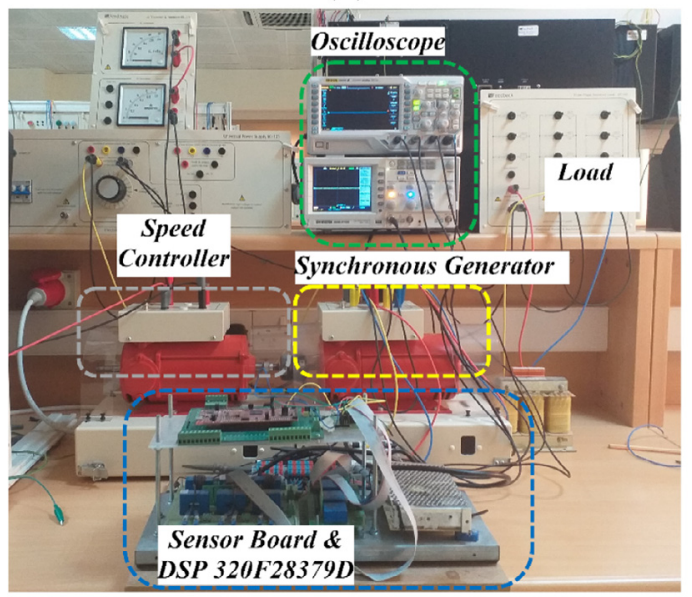

(b)

Fig. 15. Considered experimental setup - (a) Block diagram of the experimental setup and (b) Experimental platform.

synchronous generator. Voltage at the load side is measured by a LEM LV25-P sensor. The experimental data of the grid voltage is processed by using a Texas Instruments TMS320F28335 digital signal processor. The sampling frequency is set to $10 \mathrm{kHz}$. The studied techniques are implemented in Simulink and embedded into the DSP by using Matlab2017b/Simulink and C2000 Code Generation Tools v6.0.0 software. The results are observed in a digital storage oscilloscope (Rigol DS1054Z) connected to Digital to Analog Converter (DAC) module.

In the first test, sudden change of $-2 \mathrm{~Hz}$ in frequency is considered. Experimental results in this case are given in Fig. 16(a). They show that the proposed technique converged rapidly within $50 \mathrm{~ms}$ whereas ISOGIPLL took 80msec. Moreover, ISOGI-PLL has significant peak overshoot compared to the proposed technique. It should be noted that the proposed technique is showing second-order response with peak overshoot. This was not the case in HIL experimental study. This is because the frequency change happened together with phase change as shown in the grid voltage signal of Fig. 16(a).

In the second test, harmonics robustness of the two techniques are considered. In this test, the grid voltage is suddenly corrupted with harmonics. Experimental results in this case are given in Fig. 16(b). They show that both techniques have similar performance in presence of harmonics. It is to be noted here that the proposed technique has 1 parameter to tune while ISOGI-PLL has 4.

\section{Conclusions}

This paper was dedicated to unknown grid frequency estimation in the presence of DC offset. A low-pass filtering or additional tuning parameter free simple technique was proposed for this purpose. The proposed technique has simple structure and overcome the tuning limitation of similar other techniques available in the literature. It is easy-to-implement and suitable for both single and three-phase grid voltages. Comparative experimental results demonstrated that the proposed technique performs either better or similar to another state- 
ISOGI-PLL

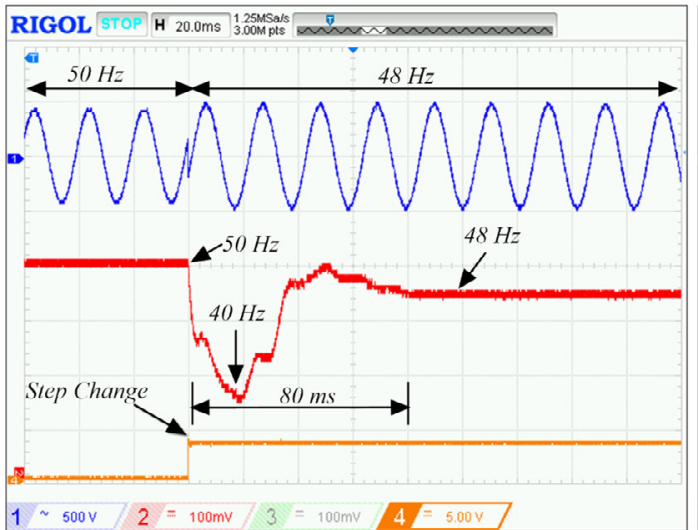

Proposed

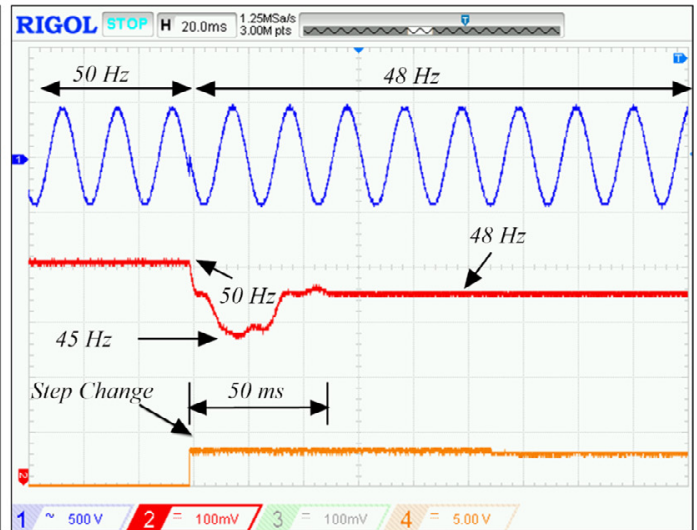

(a)

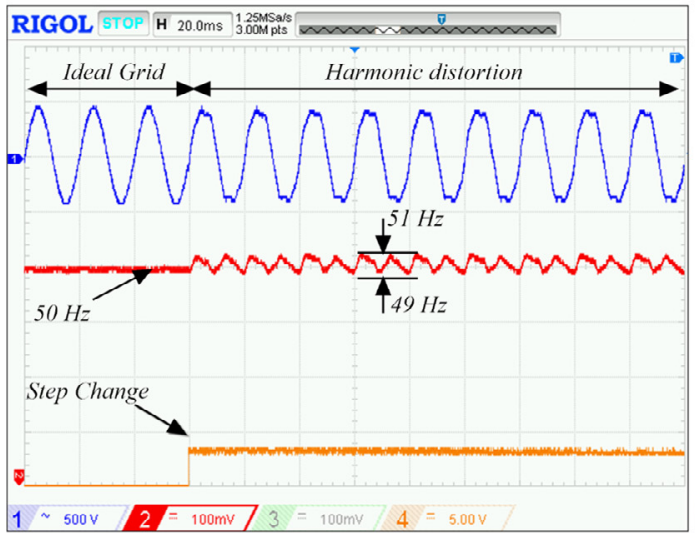

(b)

Fig. 16. Experimental test results using the setup in Fig. 15: (a) Frequency step test and (b) Distorted grid voltage test.

of-the-art technique without any additional tuning gain. This clearly demonstrates the suitability of the proposed technique.

\section{CRediT authorship contribution statement}

Hafiz Ahmed: Conceptualization, Methodology, Software, Validation, Writing - original draft. Samet Biricik: Validation, Writing review \& editing. Mohamed Benbouzid: Writing - review \& editing, Supervision.

\section{Declaration of Competing Interest}

The authors declare that they have no known competing financial interests or personal relationships that could have appeared to influence the work reported in this paper.

\section{References}

[1] F. Tlili, A. Kadri, F. Bacha, Advanced control strategy for bidirectional three phase AC/DC converter, Electr. Power Syst. Res. 179 (2020) 106078.

[2] A. Sahli, F. Krim, A. Laib, B. Talbi, Model predictive control for single phase active power filter using modified packed U-cell (MPUC5) converter, Electr. Power Syst. Res. 180 (2020) 106139.

[3] M. Merai, M.W. Naouar, I. Slama-Belkhodja, E. Monmasson, An adaptive PI controller design for DC-link voltage control of single-phase grid-connected converters, IEEE Trans. Ind. Electron. 66 (8) (2019) 6241-6249.

[4] A. Safa, E.M. Berkouk, Y. Messlem, A. Gouichiche, A robust control algorithm for a multifunctional grid tied inverter to enhance the power quality of a microgrid under unbalanced conditions, Int. J. Electr. Power Energy Syst. 100 (2018) 253-264.

[5] E. Can, Novel high multilevel inverters investigated on simulation, Electr. Eng. 99
(2) (2017) 633-638.

[6] A. Rahoui, A. Bechouche, H. Seddiki, D.O. Abdeslam, Grid voltages estimation for three-phase PWM rectifiers control without AC voltage sensors, IEEE Trans. Power Electron. 33 (1) (2018) 859-875.

[7] S.A. Belfedhal, E.M. Berkouk, Y. Messlem, Analysis of grid connected hybrid renewable energy system, J. Renew. Sustain. Energy 11 (1) (2019) 14702.

[8] M. Mansour, M. Mansouri, S. Bendoukha, M. Mimouni, A grid-connected variablespeed wind generator driving a fuzzy-controlled PMSG and associated to a flywheel energy storage system, Electr. Power Syst. Res. 180 (2020) 106137.

[9] E. Can, H.H. Sayan, A novel SSPWM controlling inverter running nonlinear device, Electr. Eng. 100 (1) (2018) 39-46.

[10] A. Benali, M. Khiat, T. Allaoui, M. Denai, Power quality improvement and low voltage ride through capability in hybrid wind-PV farms grid-connected using dynamic voltage restorer, IEEE Access 6 (2018) 68634-68648.

[11] E. Can, The levels effect of the voltage generated by an inverter with partial source on distortion, Int. J. Electron. (2020) 1-22, https://doi.org/10.1080/00207217. 2020.1726496 .

[12] S.-A. Amamra, K. Meghriche, A. Cherifi, B. Francois, Multilevel inverter topology for renewable energy grid integration, IEEE Trans. Ind. Electron. 64 (11) (2017) 8855-8866.

[13] E. Can, Power regulation by couple half wave LPWM rectifier at three-phase loads, Tehnički Glasnik 13 (3) (2019) 184-191.

[14] E. Can, The modeling and analysis of a power transmission line supplied by a solar power plant, Tehnički Glasnik 12 (3) (2018) 124-130.

[15] S. Ouchen, H. Steinhart, M. Benbouzid, F. Blaabjerg, Robust DPC-SVM control strategy for shunt active power filter based on H-infinity regulators, Int. J. Electr. Power Energy Syst. 117 (2020) 105699.

[16] S. Biricik, H. Komurcugil, N.D. Tuyen, M. Basu, Protection of sensitive loads using sliding mode controlled three-phase DVR with adaptive notch filter, IEEE Trans. Ind. Electron. 66 (7) (2018) 5465-5475.

[17] S. Biricik, H. Komurcugil, Optimized sliding mode control to maximize existence region for single-phase dynamic voltage restorers, IEEE Trans. Ind. Inf. 12 (4) (2016) 1486-1497.

[18] M.C. Kisacikoglu, M. Kesler, L.M. Tolbert, Single-phase on-board bidirectional PEV charger for V2G reactive power operation, IEEE Trans. Smart Grid 6 (2) (2014) $767-775$. 
[19] J. Carmona-Sánchez, M. Barnes, J.M. Apsley, Virtual energy storage: converting an AC drive to a smart load, IEEE Trans. Energy Convers. 33 (3) (2018) 1342-1353.

[20] H. Ma, A.A. Girgis, Identification and tracking of harmonic sources in a power system using a Kalman filter, IEEE Trans. Power Deliv. 11 (3) (1996) 1659-1665.

[21] Y. Amirat, Z. Oubrahim, G. Feld, M. Benbouzid, Phasor estimation for power quality monitoring: Least square versus Kalman filter, IECON 2017-43rd Annual Conference of the IEEE Industrial Electronics Society, IEEE, 2017, pp. 4339-4343.

[22] C. Subramanian, R. Kanagaraj, Single-phase grid voltage attributes tracking for the control of grid power converters, IEEE J. Emerg. Sel. Top. Power Electron. 2 (4) (2014) 1041-1048.

[23] B.P. McGrath, D.G. Holmes, J.J.H. Galloway, Power converter line synchronization using a discrete fourier transform (DFT) based on a variable sample rate, IEEE Trans. Power Electron. 20 (4) (2005) 877-884.

[24] Y. Terriche, J.M. Guerrero, J.C. Vasquez, Performance improvement of shunt active power filter based on non-linear least-square approach, Electr. Power Syst. Res. 160 (2018) 44-55.

[25] D. Yazdani, M. Mojiri, A. Bakhshai, G. Joos, A fast and accurate synchronization technique for extraction of symmetrical components, IEEE Trans. Power Electron. 24 (3) (2009) 674-684.

[26] S. Mekhilef, M. Tarek, N. Abd. Rahim, Single-phase hybrid active power filter with adaptive notch filter for harmonic current estimation, IETE J. Res. 57 (1) (2011) 20-28.

[27] A. Kherbachi, A. Chouder, A. Bendib, K. Kara, S. Barkat, Enhanced structure of second-order generalized integrator frequency-locked loop suitable for DC-offset rejection in single-phase systems, Electr. Power Syst. Res. 170 (2019) 348-357.

[28] A. Bendib, A. Chouder, K. Kara, A. Kherbachi, S. Barkat, W. Issa, New modeling approach of secondary control layer for autonomous single-phase microgrids, J. Frankl. Inst. 356 (13) (2019) 6842-6874.

[29] H. Ahmed, M.L. Pay, M. Benbouzid, Y. Amirat, E. Elbouchikhi, Hybrid estimatorbased harmonic robust grid synchronization technique, Electr. Power Syst. Res. 177 (2019) 106013.

[30] H. Ahmed, S.-A. Amamra, M. Bierhoff, Frequency-locked loop based estimation of single-phase grid voltage parameters, IEEE Trans. Ind. Electron. 66 (11) (2019) 8856-8859, https://doi.org/10.1109/TIE.2018.2873527.

[31] H. Ahmed, M. Bierhoff, M. Benbouzid, Multiple nonlinear harmonic oscillator-based frequency estimation for distorted grid voltage, IEEE Trans. Instrum. Meas. 69 (6) (2020) 2817-2825.

[32] H. Ahmed, M. Benbouzid, On the enhancement of generalized integrator-based adaptive filter dynamic tuning range, IEEE Trans. Instrum. Meas. (2020), https:// doi.org/10.1109/TIM.2020.2982232.

[33] H. Ahmed, M. Benbouzid, Simplified second-order generalized integrator-frequency-locked loop, Adv. Electr. Electron. Eng. 17 (4) (2019) 405-412.

[34] H. Ahmed, S.-A. Amamra, I. Salgado, Fast estimation of phase and frequency for single-phase grid signal, IEEE Trans. Ind. Electron. 66 (8) (2019) 6408-6411.

[35] P. Shah, B. Singh, Adaptive observer based control for roof-top solar PV system, IEEE Trans. Power Electron. 35 (9) (2020) 9402-9417.

[36] H. Ahmed, M.L. Pay, M. Benbouzid, Y. Amirat, E. Elbouchikhi, Gain normalized adaptive observer for three-phase system, Int. J. Electr. Power Energy Syst. 118 (2020) 105821.

[37] Y. Terriche, M.U. Mutarraf, M. Mehrzadi, A. Lashab, J.M. Guerrero, J.C. Vasquez, D. Kerdoun, Adaptive CDSC-based open-loop synchronization technique for dynamic response enhancement of active power filters, IEEE Access 7 (2019) 96743-96752.

[38] A. Safa, E.M. Berkouk, Y. Messlem, Z. Chedjara, A. Gouichiche, A pseudo open loop synchronization technique for heavily distorted grid voltage, Electr. Power Syst. Res. 158 (2018) 136-146.

[39] M. Karimi-Ghartemani, Enhanced Phase-Locked Loop Structures for Power and Energy Applications, John Wiley \& Sons, 2014.

[40] Z. Chedjara, A. Massoum, S. Massoum, P. Wira, A. Safa, A. Gouichiche, A novel robust PLL algorithm applied to the control of a shunt active power filter using a self tuning filter concept, 2018 IEEE International Conference on Industrial Technology (ICIT), IEEE, 2018, pp. 1124-1131.

[41] A.A. Ahmad, M. Pichan, A. Abrishamifar, A new simple structure PLL for both single and three phase applications, Int. J. Electr. Power Energy Syst. 74 (2016) 118-125.

[42] M.E. Meral, D. Çelik, Benchmarking simulation and theory of various PLLs produce orthogonal signals under abnormal electric grid conditions, Electr. Eng. 100 (3) (2018) 1805-1817.

[43] M. Ciobotaru, R. Teodorescu, F. Blaabjerg, A new single-phase PLL structure based on second order generalized integrator, Power Electronics Specialists Conference, 2006. PESC'06. 37th IEEE, IEEE, 2006, pp. 1-6.

[44] A. Bechouche, H. Sediki, D.O. Abdeslam, S. Haddad, An adaptive neural PLL for grid synchronization, IECON 2012-38th Annual Conference on IEEE Industrial Electronics Society, IEEE, 2012, pp. 4451-4456.

[45] S.-R. Nam, J.-Y. Park, S.-H. Kang, M. Kezunovic, Phasor estimation in the presence of DC offset and CT saturation, IEEE Trans. Power Deliv. 24 (4) (2009) 1842-1849.

[46] F. Chishti, S. Murshid, B. Singh, Weak grid intertie WEGS with hybrid generalized integrator for power quality improvement, IEEE Trans. Ind. Electron. 67 (2) (2020) 1113-1123.

[47] M.L. Pay, H. Ahmed, Modeling and tuning of circular limit cycle oscillator FLL with preloop filter, IEEE Trans. Ind. Electron. 66 (12) (2019) 9632-9635.

[48] J. Matas, M. Castilla, J. Miret, L.G. de Vicuña, R. Guzman, An adaptive prefiltering method to improve the speed/accuracy tradeoff of voltage sequence detection methods under adverse grid conditions, IEEE Trans. Ind. Electron. 61 (5) (2013) 2139-2151.

[49] H.A. Hamed, A.F. Abdou, E.H. Bayoumi, E. El-Kholy, Frequency adaptive CDSC-PLL using axis drift control under adverse grid condition, IEEE Trans. Ind. Electron. 64 (4) (2017) 2671-2682.

[50] M. Karimi-Ghartemani, S.A. Khajehoddin, P.K. Jain, A. Bakhshai, M. Mojiri, Addressing DC component in PLL and notch filter algorithms, IEEE Trans. Power Electron. 27 (1) (2012) 78-86.

[51] H. Ahmed, M. Benbouzid, Demodulation type single-phase PLL with DC offset rejection, Electron. Lett. 56 (7) (2020) 344-347.

[52] S. Murshid, B. Singh, Reduced sensor based PMSM driven autonomous solar water pumping system, IEEE Trans. Sustain. Energy (2019), https://doi.org/10.1109/ TSTE.2019.2924012.

[53] B. Singh, P. Shah, I. Hussain, ISOGI-Q based control algorithm for a single stage grid tied SPV system, IEEE Trans. Ind. Appl. 54 (2) (2017) 1136-1145.

[54] V. Kaura, V. Blasko, Operation of a phase locked loop system under distorted utility conditions, IEEE Trans. Ind. Appl. 33 (1) (1997) 58-63.

[55] W. Duesterhoeft, M.W. Schulz, E. Clarke, Determination of instantaneous currents and voltages by means of alpha, beta, and zero components, Trans. Am. Inst. Electr. Eng. 70 (2) (1951) 1248-1255. 